\title{
Las sociologías del individuo revisitadas. Exploraciones entre soportes sociales, reflexividades y descentramientos de la modernidad ${ }^{1}$
}

\section{The sociologies of the individual revisited. Explorations between social supports, reflexivities and decenterings of modernity}

DOI 10.15517/rr.v99i1.37007

Nicolás Aliano ${ }^{1}$

${ }^{1}$ Consejo Nacional de Investigaciones Científicas y Técnicas (CONICET), Universidad Nacional de General San Martín (UNSAM), Argentina, nicolasaliano@ hotmail.com

Fecha de recepción: 23 de abril de 2019

Fecha de aceptación: 20 de agosto de 2019

\section{Resumen}

El artículo presenta un mapa sobre algunos de los debates contemporáneos en torno al estudio de procesos sociales de individuación. En una primera parte, revisa críticamente los desarrollos de la sociología francesa contemporánea sobre los «soportes sociales» para la conformación del individuo, así como análisis recientes de las ciencias sociales brasileñas en torno a las dimensiones materiales y reflexivas de los procesos de constitución del agente social. En esta clave, se reconstruye un debate que, evocando una misma tradición, se ha tensado entre posiciones que abordaron las condiciones sociales necesarias para la emergencia de individuos, y perspectivas que han puesto el énfasis en las prácticas reflexivas desplegadas por los agentes sociales para individualizarse. En una segunda parte, el artículo se sitúa en un caso empírico, dando cuenta del modo en que las matrices conceptuales presentadas orientaron el estudio de procesos de individuación en los sectores populares de la Argentina contemporánea. Estas indagaciones estuvieron asociadas, por un lado, a mostrar la interacción entre interpelaciones de la cultura de masas y matrices «tradicionales» de apropiación, produciendo individuos singulares. Por otro lado, estuvieron ligadas a identificar factores sociales de individuación -vinculados a las redes de sociabilidad y solidaridad- que modelan dinámicas de individuación específicas de contextos de relegación social. Completando la indagación, se presenta un balance de las contribuciones de este campo de estudios y se plantea la posibilidad de una convergencia de estas líneas, desplegadas en

\footnotetext{
${ }^{1}$ Este artículo forma parte de una investigación doctoral más amplia, titulada: Aliano, N. (2015) Música, afición y subjetividad entre seguidores del Indio Solari. Un estudio sobre procesos de individuación en sectores populares. Tesis de doctorado en Ciencias Sociales, Universidad Nacional de La Plata. La misma fue financiada con una beca doctoral del Consejo Nacional de Investigaciones Científicas y Técnicas (CONICET).
}

\section{(c) (1) $\Theta \Theta$}

Este obra está bajo una licencia de Creative Commons Reconocimiento-NoComercial-SinObraDerivada 4.0 Internacional. 
paralelo. Con ello, se propone un enfoque que integre los aspectos «culturales» $\mathrm{y}$ «sociales» en el estudio de las dinámicas de individuación.

Palabras clave: Argentina, Individuación, Reflexividad, Sectores populares, Soportes sociales.

\begin{abstract}
The article presents a map of contemporary debates about the study of social processes of individuation. Firstly, it analizes the developments of contemporary French sociology around the «social supports» of the person, and the developments of Brazilian social sciences about material and reflective dimensions of the constitution of empirical forms of social agent. A debate is rebuilt between positions that analyzed the social conditions necessary for the emergence of individuals, and others that emphasized the reflective practices deployed by social agents to individualize. In a second part, the article is placed in an empirical case, and analizes the way in which the conceptual matrices presented guided the study of individuation processes in the popular sectors of contemporary Argentina. These inquiries were associated, on the one hand, to show the interaction between mass culture interpellations and «traditional» appropriation matrices, producing specific individuals. On the other hand, they were linked to identifying social factors of individuation asociated to the sociability networks- that model specific dynamics of individuation in social relegation contexts. Completing the inquiry, is presented a balance of the contributions of this field of studies and the possibility of a convergence of these lines. With this, it propose an approach that integrates the «social» and «cultural» aspects in the study of the dynamics of individuation.
\end{abstract}

Keywords: Argentina, Individuation, Reflexivity, Popular sectors, Social supports.

\title{
Introducción
}

Una serie de desarrollos recientes, con epicentro en la sociología francesa, han apuntado a visibilizar un proceso de individualización de diversos lazos sociales en las sociedades contemporáneas (Rosanvallon 1997; Castel 1997). Estos procesos tendrían lugar de modos específicos y diferenciales en distintos segmentos de las sociedades contemporáneas, modulando dinámicas de individuación emergentes para el análisis. Asimismo, para el caso de las sociedades latinoamericanas, algunos autores destacan que, en la región y sin que la igualdad se imponga enteramente sobre la jerarquía tradicional, las demandas de horizontalidad se consolidarían en diversas relaciones sociales, delineando nuevos perfiles de persona (Martuccelli 2010). Otros trabajos, atentos a los sentidos ambiguos de dichos procesos, han descrito un panorama de una individualización creciente de los sectores populares (Svampa 2009; Kessler y Merklen 2013). Estos trabajos destacan la tensión entre instancias clásicas de inscripción colectiva (el barrio, la familia, la comunidad) y dinámicas individualizantes ligadas al consumo de masas, la privatización

\section{(c) (1) $\$(\Theta$}

Este obra está bajo una licencia de Creative Commons Reconocimiento-NoComercial-SinObraDerivada 4.0 Internacional. 
de los riesgos sociales y las exigencias de «activación» que prescriben las instituciones (Kessler y Merklen 2013).

Estas observaciones buscan captar un proceso aún emergente y con sentidos inciertos, que resitúa, en el foco del análisis, un problema clásico del cruce entre la sociología y la antropología: el problema del individuo y de las condiciones sociales de su constitución. En este plano, la constatación histórica de una creciente «individualización de lo social», dialoga con un creciente interés teórico por el estudio de «lo social a escala individual»-que ha conducido, por ejemplo, a postular la necesidad de un programa de investigación para una «sociología psicológica» (Lahire 2005)-. El «individuo», como valor o como proceso, se ha resituado en el foco del análisis.

Este artículo se ubica en ese locus y, sin pretensión de exhaustividad, tiene como objetivo presentar algunos de los principales debates y posicionamientos contemporáneos en torno al estudio de los procesos sociales de constitución de «individuos». A su vez, y de manera complementaria, profundiza en el análisis de dicho debate desde la sistematización de sus implicancias en un campo específico de indagaciones empíricas. En este último plano se reconstruyen las matrices de análisis que han guiado el estudio de la individuación entre las clases populares contemporáneas, en el caso de Argentina. Con ello, se busca dar cuenta de la operatividad de estos debates para el análisis social situado. Correlativamente aspira a mostrar algunos de los desafíos que abren los análisis de contextos divergentes a los de las sociedades centrales, para la comprensión de la individuación como proceso social.

El recorrido que se propone es el siguiente: en la primera sección presento el contexto de discusión donde la problemática (con convergencias y énfasis diferenciales que se buscan registrar) ha vuelto a ganar centralidad y productividad: la sociología francesa contemporánea y su cruce con la antropología brasileña. De los debates de la antropología brasileña, destacaremos la problematización de la articulación de las dimensiones «ideológicas», «materiales» $\mathrm{y}$ «reflexivas» en los procesos de constitución de agentes sociales (sección 2); de los debates de la sociología francesa analizaremos la problematización en torno a los «soportes sociales» a las dinámicas de individuación (sección 3)². En líneas por ahora generales, se reconstruye aquí un debate que,

\footnotetext{
${ }^{2}$ Cabe destacar que la discusión presentada aquí es una específica en torno al análisis de la conformación social del individuo en el contexto francés que, sin embargo, no agota el debate. En este sentido, una línea no profundizada por cuestiones de extensión, pero especialmente gravitante en las indagaciones actuales, es aquella que explora la producción social del individuo destacando el carácter plural del actor social. En esta línea se inscriben los desarrollos de Bernard Lahire. Al respecto, a modo de condensación de esta perspectiva refiere: «la captación de lo singular en cuanto tal, es decir, del individuo como producto complejo de diversos procesos de socialización, fuerza a ver la pluralidad interna del individuo: lo singular es necesariamente plural» (Lahire 2005, 163). Adicionalmente el/la lector/a puede remitirse a: Lahire, B. (2013), L'individu dans les plis singuliers du social. Individus Institutions Socialisations. Paris: La Découverte. Una exploración empírica de estas hipótesis para el análisis de trayectorias biográficas de consumo cultural puede encontrarse en Aliano, N. (2018) «Gusto 'omnívoro', proyectos personales y nuevas femineidades. Una exploración a partir del caso de una aficionada a la música». Descentrada. Revista interdisciplinaria de feminismos y género, 2 (1): 1-17.
} 
muchas veces evocando una misma tradición, se ha tensado entre posiciones que han reflexionado sobre las condiciones sociales necesarias para la emergencia de individuos, y otras que han puesto el énfasis propiamente en las prácticas de individuación desplegadas por los agentes sociales. Este camino se completa presentando los antecedentes y reverberaciones de estos debates en el análisis de procesos de individuación entre los sectores populares en Argentina (sección 4).

A la luz de este debate, en la sección 5 se propone una posible vía de convergencia de las perspectivas presentadas previamente para el análisis de la individuación como proceso, destacando las implicaciones de ese desplazamiento. Por último, en las reflexiones finales, integraremos este análisis a las tesis más amplias sobre los desafíos al estudio de los procesos de individuación en sociedades periféricas a la modernidad.

\section{El debate. Individuación e individualización}

¿Cuál sería, exactamente, ese modelo de persona -«el individuo moderno» que resultaría necesario relativizar para describir positivamente diversos procesos sociales de producción de individuos? Antes de delinear las estrategias para su relativización, pareciera del todo necesario detenernos a precisar sus dimensiones. Así las sintetiza Danilo Martuccelli:

En primer lugar, [...] fue concebido como un sujeto autónomo, es decir poseedor de cierta capacidad para fijar él mismo las orientaciones de su acción. En segundo lugar, fue considerado, durante el paso de la «comunidad» a la «sociedad», como un individuo independiente. En tercer lugar, [...] fue concebido, con ayuda especialmente de la expansión del proceso de racionalización, cómo dotado de una gran capacidad de autocontrol personal. Por último, y en apariencia contra esta última exigencia, se impuso la figura de un individuo expresivo, que debía manifestar fuera de él, por sus actos, lo que es en el interior $(2007,38)$.

La representación dominante del individuo a partir de dichos conceptos (sujeto autónomo, independiente, con capacidad de autocontrol y expresivo), postuló la búsqueda -señala Martuccelli«de un acuerdo tácito entre esos procesos, inseparablemente normativo y descriptivo» $(2007,38)$. Una vez precisadas las dimensiones de esta noción dominante de «individuo», aboquémonos a examinar algunas de las vías que llevaron a su relativización.

Existe cierto consenso entre los antropólogos en situar el inicio del debate en torno a la noción de persona en el trabajo de Marcel Mauss de 1938, Sobre una categoría del espíritu humano: la noción de persona y la noción del «yo». En ese trabajo, inscripto en el proyecto inicial de Durkheim de una historia social de las categorías del espíritu humano, Mauss busca demostrar el carácter social de la noción y a la vez señalar la especificidad radical del modelo moderno de persona.

\section{(c) (1) $\$(\Theta$}

Este obra está bajo una licencia de Creative Commons Reconocimiento-NoComercial-SinObraDerivada 4.0 Internacional. 
Según Goldman, Mauss trata allí de exponer cómo, a partir de un «fondo primitivo de indistinción», la noción de persona que se pretende de existencia universal, «se destaca lentamente de su enraizamiento social para constituirse en categoría jurídica, moral e incluso lógica» (Goldman 1999, 22). De acuerdo con la lectura de Goldman, coexistiría en este proyecto una vertiente «evolucionista» y otra «relativista»: si, por un lado, este plan daría lugar a pensar la variedad y variabilidad empírica de las nociones de persona (su carácter «relativista»), por el otro se inscribiría en un proceso evolutivo en el cual la emergencia de la noción correspondería al desenvolvimiento de un principio contenido desde el inicio, en algo así como «las formas elementales de la individualidad» (Goldman 1999, 26).

Esta tensión -que, en el caso de Mauss, se resolvería en favor de su «evolucionismo»- podría encontrarse en una parte de la tradición sociológica francesa posterior, que retomó la problematización del individuo. En ese sentido, Corcuff (2013) destaca esta doble dimensión presente en el debate contemporáneo, recuperando la distinción de Louis Dumont (1970) entre «individuo-empírico» (miembro de cualquier sociedad y cultura) e «individuo-valor» (específico de nuestra tradición cultural). Corcuff $(2013,105)$ encuentra que, aquello que denomina «las nuevas sociologías» francesas, se han abocado a dos tipos de problemas. Por un lado, 1) el problema de la individuación: la singularidad del individuo y propiedades que remiten a la misma, un proceso presente en toda sociedad -que a su vez adopta formas específicas en las sociedades individualistas, en las que se valora la individualidad-. (Corcuff refiere aquí a perspectivas como la de «habitus individual» de Bourdieu (2007) y la de «modos de subjetivación» de Foucault (2008)). Por otro lado, distingue (2) el problema de la individualización: la idea de una individualización mayor de los sujetos en las sociedades contemporáneas (el autor refiere aquí a «elucidaciones históricas», como la de Dumont (1970) en su historia comparada de las sociedades holistas e individualistas, la de Elias (2009) vinculada al «proceso de civilización» en Occidente, o la de Castel (1997) en su historia del individualismo moderno en relación a la constitución del Estado social). ${ }^{3}$

Señalado esto, parecería que mientras el primer polo problemático se inscribe más fácilmente en la vertiente relativista inaugurada por Mauss, el otro polo parece correr mayor riesgo de habilitar una tonalidad evolucionista u homogeneizante en el análisis.

Una vez bosquejado este mapa general de movimientos veamos cómo, en sus derivaciones en la antropología brasileña -centralmente a partir de la relectura de Dumont- se buscó resolver esta tensión. En este punto nos centraremos fundamentalmente en la reelaboración crítica de la cuestión en el trabajo de Goldman (1999), quien propone un análisis que integre las dimensiones «ideológicas» y «materiales» de la individuación, sin reponer una razón evolucionista o

\footnotetext{
${ }^{3}$ Aquí se presenta una estilización del desarrollo presentado por Corcuff. La persona lectora puede remitirse a Corcuff (2013, 105-126) para una mayor profundidad.
}

\section{(c) (1) $\$($}

Este obra está bajo una licencia de Creative Commons Reconocimiento-NoComercial-SinObraDerivada 4.0 Internacional. 
globalizante. Posteriormente, retomaremos el debate francés a la luz de la problematización de la noción de «soporte».

\section{La relectura de Louis Dumont en la antropología brasileña: de las ideologías englobantes a las prácticas múltiples}

De acuerdo con Goldman (1999), la tensión entre «relativismo» y «evolucionismo» persiste en la obra de Louis Dumont (tal vez porque Dumont en realidad buscó atender a ambos problemas sistematizados por Corcuff). Me detendré a desarrollar el argumento, dada la importancia de la obra de Dumont en esta cuestión y de su relevancia, en particular, para la antropología brasileña. En este sentido, de acuerdo a las palabras de Duarte (1986), es en la obra de Dumont donde se podría hallar «la más radical y articulada relativización de la noción moderna de persona»; y ello «gracias a su definición teórica estricta de 'jerarquía' o 'pensamiento jerárquico' y consecuente especificación de la ideología del 'individualismo'» (1986, 40). En este movimiento de relativización y contra la pretendida universalidad de la noción de individuo, Dumont distingue entre el individuo empírico y universal, («infra-sociológico», de acuerdo a la expresión de Goldman (1999)) del individuo-valor, central para la configuración ideológica moderna. Una vez operada esta distinción, Dumont (1970) opone, de un lado las sociedades holistas, «tradicionales»-que pondrían el acento «sobre la sociedad en su conjunto» conforme a una lógica jerárquica en la cual los individuos empíricos son dependientes de un «todo»-; y de otro lado, las sociedades individualistas «modernas», que privilegiarían las unidades individuales, en torno a valores de «libertad» e «igualdad».

Es por ello que Goldman concluye que, la cuestión del individuo o de la persona en Dumont, es en realidad transpuesta hacia la de una ideología que la instaura como valor dominante, y que «el verdadero problema de Dumont no es el 'individuo', sino el 'individualismo'» (Goldman 1999, 26). En este marco, el autor realiza una serie de consideraciones críticas, de las cuales recupero las dos centrales.

En primer lugar, una crítica al alto nivel de generalidad y abstracción en que se mueve el planteo de Dumont. Goldman observa que oponiendo globalmente «holismo» e «individualismo» en el caso de Dumont (o «jerarquía» e «individuo», en el de Roberto Da Matta para el contexto brasileño, al cual hace extensiva la crítica), se deja escapar la posibilidad de utilizar esas nociones como instrumentos heurísticos, en un sentido operativo y metodológico; convirtiéndolos en «principios teóricos al interior de los cuales es posible encajar lo que se quiera con un mínimo de esfuerzo» (Goldman 1999, 35). Esta crítica se encuentra presente en otros autores brasileños. Gilberto Velho (1997), señala que, cuando la investigación se aproxima a coyunturas históricas específicas y al nivel etnográfico propiamente dicho, las oposiciones binarias que organizan el esquema dumontiano (holismo/individualismo, jerarquía/igualitarismo) muestran sus límites heurísticos. Asimismo, Duarte $(1986,48)$ pone de relieve lo que denomina la cuestión de los

\section{(C) (1) $\Theta \Theta$}

Este obra está bajo una licencia de Creative Commons Reconocimiento-NoComercial-SinObraDerivada 4.0 Internacional. 
«énfasis» y las «combinaciones» presentes en cada sociedad entre diferentes aspectos del individualismo y la jerarquía.

En segundo lugar, Goldman crítica la preocupación exclusiva de Dumont por los aspectos formales («ideológicos»), que lo obliga a excluir la materialidad del individuo, relegándola a un plano «infra-sociológico». Con esa operación, de acuerdo a Goldman, «se desestima el hecho de que las culturas invisten directamente los cuerpos y que toda separación entre lo físico, lo psíquico y lo social, solo puede ser sostenible como una abstracción» (Goldman 1999, 29) ¿Solución?: «Creo que la solución» -afirma- «sería renunciar definitivamente al par real/ideología, admitiendo una materialidad generalizada manifiesta, sea en las 'ideas', sea en las cosas» $(1999,29)$.

En suma: si el primer punto crítico es central para redimensionar el análisis de las dinámicas de individuación -en análisis más situados y en coyunturas específicas-, el segundo es clave en el movimiento analítico de Goldman, ya que lo lleva a relocalizar el problema, al romper con las limitaciones del concepto de ideología que sustenta el análisis de Dumont. De modo que si sumamos los dos señalamientos: 1) la redefinición de la «escala» de análisis y 2) la integración de los aspectos formales y materiales en dichos análisis, llegamos a la noción de modos de subjetivación foucaultiana. En esta clave, Goldman afirma (1999, 35 cursivas del autor) que «a las teorías que buscan captar la sustancia de ideologías englobantes, sería preciso oponerles, consecuentemente, una analítica de los procesos inmanentes a las prácticas múltiples». Señalado esto, concluye que «esta es, se sabe, una posición desarrollada por Michel Foucault, al dedicarse, al final de su vida, al estudio de lo que denominó 'formas de subjetivación', y que, grosso modo, podríamos también llamar de 'noción de persona'» (Goldman 1999, 35; cursivas del autor).

La apuesta de Goldman, en suma, es resituar el debate en torno a la «noción de persona» en una indagación integrada de los aspectos discursivos, materiales y reflexivos de los «modos de subjetivación»; modos que son históricos y locales (y por ello singulares y específicos).

\section{La relectura de Robert Castel: pluralizar los soportes sociales para la individuación}

Partiendo del concepto de «soportes» para la individuación (Castel y Haroche 2003) y desde lo que denomina «un enfoque objetivista de la subjetividad», Robert Castel propone subrayar el modo en que el movimiento de autonomización de los individuos necesita de condiciones sociales. Castel advierte cómo la institucionalización por parte del Estado de una serie de regulaciones sociales (como las limitaciones del tiempo de trabajo, o la protección de la «esfera privada») y de protecciones (como la seguridad social, la jubilación o formas de acceso social a la vivienda), apunto a la constitución de un orden social del cual emergían grados de libertad y autonomía para los individuos. De modo que, en palabras de Merklen $(2013,74)$ «la libre disposición de 'porciones' de tiempo o el mantenimiento de los ingresos durante los periodos de inactividad permitió la emergencia de formas sociales de tipo individualista». De acuerdo a esta visión, como señala Corcuff (2013), Castel muestra, contra la perspectiva liberal que parte de la relación de

\section{(c) (1) $\$($}

Este obra está bajo una licencia de Creative Commons Reconocimiento-NoComercial-SinObraDerivada 4.0 Internacional. 
oposición entre individuo y sociedad, que la autonomía individual moderna se apoyó sobre «soportes sociales» específicos (seguridad social, estatuto salarial, etc.). Estos soportes «permiten al individuo desligarse de los azares de la vejez, de los accidentes, de la enfermedad o de la coyuntura económica, para proyectarse en el tiempo y culminar una vida personal». Se trata entonces, de «una individualidad sostenida por dispositivos de solidaridad» (Corcuff 2013, 112).

Denis Merklen (2005) sistematiza los alcances del concepto de «soporte», señalando que el mismo evoluciona sobre un doble registro teórico: «Por un lado sirve para identificar las condiciones sociales que permiten a los hombres existir 'positivamente' como individuos, esto es, identificar las bases sobre las que el individuo puede 'asentar un mínimo de autonomía'» (2005, 188). Por otra parte, «la ausencia o presencia de soportes permite a Castel identificar 'figuras' de individuo, como las de individuo 'por exceso', 'por defecto', y aun individuo 'negativo'» (2005, 188). En suma, desde esta perspectiva la preocupación es por las condiciones de posibilidad objetivas para desatar los procesos de individuación. En este sentido, y bajo la impronta durkheimiana, tanto Merklen como Castel se apartan de lo que consideran conduce a una «disolución de lo social y a una subjetivación del proceso de individuación» (Merklen 2013, 55). En palabras de Castel: «Podemos perfectamente interesarnos, como lo ha hecho recientemente Alain Touraine, en el devenir-sujeto del individuo. Sin embargo, no es ello lo que nos atañe [...], sino más bien las condiciones previas para entrar en un proceso de devenir-sujeto [...]. Yo insisto, por mi parte, en el hecho de que, para entrar en la aventura del sujeto, es necesario ante todo ser un individuo dotado de soportes de independencia» (Castel y Haroche 2003, 19).

En este cuadro, quisiera recuperar dos críticas que se le han hecho a la noción de «soporte» en la perspectiva de Castel. Una de estas críticas (1), planteada por Martuccelli (2007), tiene que ver con el carácter «reduccionista» y «estadocéntrico» del análisis de los modos de individuación y los soportes sociales; otra de las críticas (2), presentada por Corcuff (2013), se relaciona con el tinte evolucionista y homogeneizador que persistiría en el planteo. Veamos cada una de ellas.

(1) Impronta reduccionista y «estadocéntrica»: en el análisis de Castel, los «soportes» son considerados como las condiciones objetivas de posibilidad del individuo moderno, el lugar donde se pueden apoyar para constituirse en actores y delinear estrategias personales. Según Martuccelli (2007) se trata esta de una mirada restringida, anclada en la preocupación por mostrar el rol central que el Estado Social tuvo, en el contexto europeo, en la constitución del individuo moderno. Y en este caso, los soportes, «pensados a partir de su dimensión política, están demasiado relacionados con la necesidad de intervención del Estado para asegurar la cohesión social» $(2007,75)$. Sin embargo, el autor enfatiza que estos soportes pueden no ser los únicos ni los más importantes, y que, tras la visión de Castel, se encuentra la idea de que, por fuera de estos soportes institucionales, «la sociedad civil es incapaz de asegurar ella misma su cohesión» $(2007,75)$. En tal caso, el autor destaca, por ejemplo, el lugar que tienen las redes de sociabilidad en las sociedades latinoamericanas en su carácter de soportes de procesos de individuación específicos que, en estos contextos, cabe pensar como «factores de individuación» (Martuccelli 2010).

\section{(ब) (1) $\Theta$}

Este obra está bajo una licencia de Creative Commons Reconocimiento-NoComercial-SinObraDerivada 4.0 Internacional. 
A modo de balance, Martuccelli propone una definición más abarcadora de la noción de soporte, en aras de superar algunas de las limitaciones señaladas, pero sin dejar de contemplar la especificidad analítica del concepto. En este sentido el autor refiere: «No es, pues, de la constitución del individuo de lo que se trata, sino de los procedimientos por los cuales éste llega a tenerse frente al mundo. Y esos medios no son otros que el conjunto de los elementos, materiales e inmateriales, que lo vinculan a su contexto» (Martuccelli 2007, 61-62). Estos soportes, en suma, pueden ser de naturaleza múltiple: materiales, afectivos, simbólicos, relacionales; pero, en todo caso, nunca definibles a priori. Para Martuccelli constituyen el «entorno existencial» que vincula al individuo con sus medios sociales e institucionales. Desde esta perspectiva, se concluye que «la estabilidad del individuo no hay que encontrarla ni en su interioridad ni en su trabajo narrativo. La voluntad y la acción individuales reciben un importante valor agregado en función de los soportes que lo rodean» $(2007,62)$.

(2) Impronta evolucionista: la segunda de las críticas aludidas (ya implícita en el planteo de Martuccelli), apunta al proyecto de elaborar una historia del individualismo moderno en relación con la constitución del Estado Social. Corcuff (2013) señala que muchos de estos planteos históricos, a pesar de que se inscriben en una perspectiva genealógica explícitamente deudora de Foucault, adoptan un matiz evolucionista y homogeneizante. Recuperando las precauciones metodológicas del «último» Foucault, aquel del análisis de los «modos de subjetivación» (Foucault 2008b), Corcuff afirma: «Una utilización mecánica de la noción de 'individualismo' corre el riesgo de asimilar las diferencias sociohistóricas por medio de un concepto que supuestamente resume una 'evolución' homogénea, exclusiva y necesaria [...]. Desde esta perspectiva Francois Dubet señaló, a propósito de las sociedades «tradicionales/holistas» que «en ellas el individuo puede estar menos ausente de lo que suponen los relatos de rigor acerca de la Modernidad; y que el holismo es más una alteridad teórica cómoda que una realidad antropológica» (Corcuff 2013, 113).

En línea con este señalamiento, se puede encontrar en la propuesta de Martuccelli (2007) otro desplazamiento en el análisis de los «soportes», hacia una perspectiva que atiende al análisis de configuraciones locales, antes que a grandes tendencias transhistóricas. En relación a cierto uso mecanicista de la noción, Martuccelli advierte que «hay que insistir sobre el carácter muy abierto de los soportes, sobre la diversidad de sus naturalezas, así como sobre sus manifestaciones históricas [...]. Los recursos no tienen significado más que dentro de un engranaje relacional más amplio» (2007, 59-60).

En suma, bajo esta revisión de la noción de «soporte», se propone iluminar una de las dimensiones de este proceso, aquella ligada a las condiciones de posibilidad para el «devenir sujeto». Sin embargo, a su vez podría aducirse que el concepto presenta limitaciones para abordar los procesos a partir de los cuales los individuos buscan reflexivamente subjetivarse en el plano de la cultura, más allá de la existencia de «soportes» y a partir de diversos repertorios no contemplados. Este es un punto que, contrastando miradas, habilita la propuesta de Goldman.

\section{(ब) (1) $\otimes \Theta$}

Este obra está bajo una licencia de Creative Commons Reconocimiento-NoComercial-SinObraDerivada 4.0 Internacional. 
A modo de balance: tanto desde los debates en el seno de la antropología brasileña como desde los de la sociología francesa, se confluye en una crítica de las visiones de las «ideologías englobantes». Dicha crítica se despliega en pos de un análisis operativo de estas oposiciones en contextos históricos y sociales delimitados, integrando el análisis de prácticas e ideologías en la configuración de dinámicas de individuación específicas. Y esta convergencia, como observamos, se realiza con acentuaciones diferenciales en cada propuesta, pero que se inspiran o retoman una concepción de la subjetividad en la que se percibe la común deuda con los desarrollos foucaultianos.

\section{El individuo en el mundo popular: dos líneas de investigación en el caso de Argentina}

Una vez bosquejado este mapa, en esta sección se propone mostrar las reverberaciones del debate presentado en el análisis argentino de las dinámicas de individuación entre los sectores populares contemporáneos. Se trata de un debate que, en buena medida, retoma las matrices identificadas aquí. Recuperaré dos perspectivas de análisis que propusieron dar respuesta a esta pregunta: me refiero, por un lado, a los trabajos de Semán (2006, 2007), inspirados en la tradición de la antropología brasileña; y, por el otro, a los trabajos de Merklen (2005) y Kessler y Merklen (2013), inscriptos en la tradición de la sociología francesa de Robert Castel.

\section{La individuación reflexiva: análisis de procesos de individualización}

¿Cómo se configuran individuos empíricamente describibles? Al abordar esta pregunta, es posible encontrar en el interior de los trabajos de Pablo Semán -como el mismo autor refiere (Semán 2006, 34)- dos tipos de análisis. Por un lado, indagaciones centradas en la descripción de las oposiciones globales que organizan un epicentro cultural propio de los sectores populares: se trata, en este sentido, de la identificación de nociones holistas, relacionales y jerárquicas del agente en dichos contextos, que se distinguen de pautas que acentúan la igualdad y la autonomía propias de la cultura de las clases medias. Por otra parte, análisis en lo que, a partir de indagaciones locales, recupera la articulación contingente de reglas, discursos y prácticas en configuraciones específicas de agentes.

En la primera línea, para visibilizar y subrayar esa diferencia entre la cultura de las clases medias y la cultura de los sectores populares, Semán se inscribe en la senda de Duarte (1986), mostrando que «la diferencia cultural implica una diferencia en las categorías de persona» (Semán 2006, 33). En esta línea, el autor identifica una «matriz de gestación cultural» (con características

\section{(ब) (1) $\Theta \Theta$}

Este obra está bajo una licencia de Creative Commons Reconocimiento-NoComercial-SinObraDerivada 4.0 Internacional. 
cosmológicas ${ }^{4}$, holistas y relacionales) que, como sedimento histórico, regularía diversos procesos de recepción cultural en el mundo popular, en tensión con los imperativos de la modernidad. Dicha matriz es concebida como «un sistema estructurante con dimensiones cognitivas y sensitivas que influyen en el proceso de gestación de significaciones y prácticas» (Míguez y Semán 2006, 21), y su presencia destacaría las limitaciones del proyecto modernizante en la región. ${ }^{5}$

Por otro lado, en la segunda senda referida destaca la influencia de Goldman (1999), según el cual, como en parte ya señalamos, «preservar la problematización del agente no significa buscar [...] el efecto de ideologías constituyentes -el individualismo, el tradicionalismo-, sino investigar el plano de articulación contingente de reglas, discursos y objetos en el que las ideologías son derivadas y se tornan eficaces» (Goldman, citado en Semán 2006, 33). Con ello, observamos que se retoma la crítica al alto nivel de generalidad de oposiciones globales del tipo «holismo» e «individualismo», planteadas en un nivel puramente «formal» (Goldman 1999) y «homogeneizante» (Corcuff 2013).

Bajo esta segunda impronta -la que aquí nos interesa destacar-, una serie de trabajos de Semán han mostrado, para el ámbito argentino, modos de configuración del agente entre los grupos populares delineados en la imbricación de tramas culturales y recursos provenientes de la cultura de masas o de nuevas formas de religiosidad. En esta clave, el autor ha evidenciado el modo en el que la literatura de autoayuda articula, en ciertos lectores de Paulo Coelho, tradiciones de creencia previas (asociadas al catolicismo, por ejemplo) con nuevas espiritualidades que enfatizan la autonomía subjetiva (Semán 2006). Asimismo, de igual manera analiza la recepción de la teología de la prosperidad y la literatura de autoayuda en síntesis novedosas entre creyentes pentecostales y católicos del Gran Buenos Aires (Semán 2006). En otras exploraciones examina la influencia de la psicologización entre sujetos católicos y pentecostales de un barrio popular del Gran Buenos Aires, así como el modo de imbricación de dicha influencia con las experiencias religiosas de estos sujetos (Semán 2007). Por otra parte, Semán y Gallo (2008) indagan las relaciones entre rock y religión a partir del análisis de una banda de rock evangélico.

Todos estos trabajos informan, desde un movimiento de singularización que concretiza las especificidades de cada caso, procesos de individuación tensados por principios «cosmológicos» de acogida e imperativos individualizantes de diversas interpelaciones culturales, como la literatura

\footnotetext{
${ }^{4}$ Autores como Martín (2007) y Semán (2006) conciben la «dimensión cosmológica» de la experiencia popular como la presencia de un tipo sensibilidad por la cual lo sagrado es, antes que un plano «trascendental», una dimensión más y actuante de la realidad.

${ }^{5}$ En este sentido, Semán afirma: «La cultura de los grupos populares urbanos de Latinoamérica [...] no es una matriz 'otra' en abstracto. Frente a diversas versiones del impulso modernizante sostenido por las elites, se ha moldeado aquilatándolo en composiciones de una configuración específica: priorizando los valores de la familia [...], la localidad [...], la reciprocidad [...] y el trabajo (la capacidad de combinar 'fuerza', 'corazón' y templanza en dosis apropiadas al hombre y la mujer y en todo lo que esto difiere del 'desarrollo y la realización personal' -ideologemas de los grupos afinados con la modernidad-)» (Semán 2006, 45).
}

\section{(c) (1) $\$($}

Este obra está bajo una licencia de Creative Commons Reconocimiento-NoComercial-SinObraDerivada 4.0 Internacional. 
de autoayuda, la teología de la prosperidad, el psicoanálisis o el rock. Y, en todos los casos, se trata de una «tensión» o una «fricción» que nunca se reduce a un juego de suma cero: lo que se produce, en cada caso, son «síntesis específicas» entre prácticas, discursos y agentes. De modo que todos estos trabajos aluden -con el acento puesto en los procesos reflexivos por los cuales los propios actores pueden subjetivarse a partir de diversos recursos- a la descripción de una corriente de individuación entre los sectores populares, que combina diversas tendencias individualizantes con lo que se denomina una «visión del mundo cosmológica» que las recibe, configurando modos del agente específicos.

\section{Los soportes sociales del individuo: la individuación popular como inscripción territorial}

Es posible advertir en la perspectiva desarrollada por Denis Merklen (2005) un diálogo con el análisis aludido en torno a una «matriz cultural», que interviene mediando la recepción cultural entre los grupos populares. En este sentido, podríamos pensar que Merklen propone otra mediación, ya no pensada desde un sedimento cultural, sino desde un sistema de integración. Este desplazamiento lo lleva a ver una situación de individuación específica, allí donde Semán (2006) identifica una diferencia cultural.

Merklen centra su análisis en las formas de «inscripción territorial»: el sistema de solidaridades anclado en lo barrial, que los sujetos populares elaboran positivamente frente a la desafiliación de un sistema de integración socavado. El análisis de Merklen se desplaza hacia la trama de solidaridades y sociabilidades, las formas de inscripción social que otorgan nuevos modos de integración (aunque precaria, múltiple, o inestable), a la luz de la desestructuración de los mecanismos de integración social de la «sociedad salarial».

Detrás de este desplazamiento se encuentra el referido concepto de «soportes» para la individuación de Castel. Partiendo de esta idea teórica para pensar la situación del contexto argentino de fines de los 90, marcado por la desafiliación social, Merklen encuentra la clave para entender un tipo de figura de individuo: «es precisamente en el juego que se produce entre la naturaleza de los soportes que sostienen al individuo para enfrentar un contexto particularmente exigente y la naturaleza inestable de ese mismo contexto, que el cazador ${ }^{6}$ surge como una figura de individuo propia de los mundos populares» (Merklen 2005, 188-189).

Estas consideraciones son las que llevan al autor a abordar ciertos rasgos culturales de los sectores populares (el carácter relacional que advierte Semán, por ejemplo), como elaboración de

\footnotetext{
${ }^{6}$ La figura del «cazador» elaborada por Merklen (2005) alude a un tipo de conducta individual regida por la urgencia de la pobreza, la vulnerabilidad laboral y el despliegue, en dichos contextos, de estrategias de supervivencia. En este sentido, es definida en oposición a la metáfora del «agricultor», que alude a una vida previsible y proyectable en el largo plazo, propia del trabajador asalariado inscripto en un régimen laboral estable, con seguridades y servicios sociales.
} 
una experiencia de inscripción territorial signada por las múltiples afiliaciones que elaboran los sujetos populares en la estructuración de su experiencia cotidiana. En otras palabras, si bien Merklen comparte la idea de una «matriz cultural» según la propuesta de Semán y -con algunas variaciones- sus características, tiende a reenviar estos rasgos culturales (carácter cosmológico y relacional de la cultura popular) a los modos de inscripción social y los soportes colectivos que funcionan como condición de posibilidad para los procesos de individuación, y no a un habitus o sedimento cultural como sistema estructurante de representaciones y prácticas. En sus palabras:

el desarrollo de estas experiencias depende igualmente de una lógica interna de funcionamiento de los barrios. Cuanto más masiva es la precariedad y más fallan las instituciones, más multiplican los habitantes sus pertenencias. En efecto, el territorio de los barrios se constituye a partir de la superposición de círculos de pertenencia: iglesias, bandas de jóvenes, redes de tráficos diversos, el grupo de la olla popular y el de guardería, etc. En un contexto de precariedad y de inestabilidad, estos círculos se entrelazan por tres razones: primero, porque ninguno de estos grupos tiene recursos suficientes como para estabilizar sus actividades [...]. Segundo, porque cada organización barrial establece un lazo específico con el sistema político [...]. Tercero, porque los individuos y los hogares deben multiplicar sus afiliaciones para dotarse del mayor número de coberturas y para anticipar todo lo posible toda clase de riesgos. (Merklen 2005, 147-148).

El barrio, en la perspectiva de Merklen, se conforma como la base principal para la estabilización de la experiencia. El entrelazamiento de círculos de sociabilidad que describe es lo que estructura y marca el tono de la vida colectiva en el mundo popular. De ello se derivan dos resultados algo diferentes. Mientras Semán advierte cierta lógica cultural entre los grupos populares (holismo o escaso individualismo de los sujetos, lo que le serviría para discutir la visión de la modernidad como mito irrefrenable y homogeneizador), para Merklen la densidad relacional de las culturas populares no es señal de las dificultades que encontraría el individuo para emerger (como proceso de individuación), o de los límites del individualismo (como ideología moderna), sino de una situación de individuación específica del mundo popular que permitiría contener la precariedad de forma parcial. Allí hay una situación de individuación específica que aparece como una forma de socialización determinada por dos factores: el carácter inestable y precario de la cotidianeidad del medio popular, y las formas de inscripción colectiva tejidas como respuesta a la precariedad (Merklen 2005, 173). Se trata, ya no de una reflexión sobre los límites o diferenciales de implantación de la modernidad, sino de los soportes colectivos que funcionan como condición de posibilidad de procesos de individuación al interior de los sectores populares contemporáneos:

Se puede fácilmente observar que este mundo relacional del que estamos proporcionando algunas características no tiene nada de «tradicional». Al contrario: como constitutivo de la experiencia popular contemporánea, se debe afirmar que es perfectamente «moderno». No es tradicional porque el tipo de vínculo que segrega no causa el sofocamiento del individuo. [...] La prueba de que lo

\section{(c) (1) $\$(\Theta$}

Este obra está bajo una licencia de Creative Commons Reconocimiento-NoComercial-SinObraDerivada 4.0 Internacional. 
relacional contemporáneo no tiene nada de tradicional la encontramos efectivamente en la evolución de estas nuevas formas de lo relacional, hecho que evidencia que ofrecen una posibilidad de resistencia tanto mayor cuanto que no estructuran enteramente lo social: a menudo se debilitan, hasta el punto de desaparecer, tan pronto como el Estado y el trabajo recuperan su lugar (Merklen 2005, 186).

Para Merklen la estructuración de la experiencia cotidiana, si bien está «anclada» en lo barrial, no se reduce a lo barrial, ni es lo barrial como sistema socialmente cerrado y autosuficiente. Recuperando el carácter contingente de los soportes a la individuación, Merklen se preocupa por elaborar un análisis dinámico de la situación de individuación específica del mundo popular contemporáneo. En este sentido, la crítica en relación al «estadocentrismo» implícito en el análisis de Castel como base para abordar la individuación social, le cabe parcialmente a los trabajos referidos de Merklen. En principio porque, conforme lo ya señalado, la reelaboración del concepto de «soporte» a la luz del concepto de «inscripción territorial», pone el eje precisamente en las formas de sociabilidad que permiten contener la precariedad emergente de la crisis de un tipo de integración social (derivado de las regulaciones del Estado Social en Argentina). En este caso, el análisis de Merklen ilumina una complejidad: más que mostrar la incapacidad de la sociedad civil de garantizar su cohesión, muestra el modo en el que, en la experiencia de los sectores populares, lo político declina en lo social: las formas de politicidad se inscriben en las formas de sociabilidad.

En trabajos más recientes de Merklen, en coautoría con Kessler, se analizan estas dinámicas de individuación en sus prolongaciones en el periodo que se abre a partir del 2003. Los autores señalan que la recuperación de la actividad económica en Argentina provoca una inflexión entre el mundo de los noventa y la situación de la postconvertibilidad. Sin embargo, al mismo tiempo destacan que, en un contexto de reactivación económica sostenida en el que abundan el trabajo, la actividad y el consumo, el empleo protegido y estable todavía resulta inaccesible para una parte importante de los sectores populares (Kessler y Merklen 2013, 13). Este cuadro, desde su punto de vista, promovería una triple situación: 1) La persistencia de lógicas de «cazadores» entre quienes ya no están integrados al salariado. 2) Una «extraordinaria reelaboración moral» entre las clases populares, signada por el principio de legitimación del «proveedor» (que «avala la conducta de quien trae bienes o dinero a la casa y deja en segundo plano el origen más o menos lícito o ilícito de esos recursos $(2013,15) »$. 3) Una redefinición del lugar subjetivo de la experiencia del consumo, en el que este «pasa a ser el origen de cierta respetabilidad social, una forma de distinción y de prestigio que no puede ya fundarse en la disciplina del trabajador asceta o 'sacrificado'» (Kessler y Merklen 2013, 15). Este proceso, en suma, de acuerdo a los autores, estaría en la base de las dinámicas de individuación contemporáneas, tensadas entre formas de inscripción colectivas, diversas exigencias institucionales de «responsabilización» individual, e imperativos individualizantes en torno al lugar del consumo en la elaboración subjetiva.

\section{(c) (1) $\$($}

Este obra está bajo una licencia de Creative Commons Reconocimiento-NoComercial-SinObraDerivada 4.0 Internacional. 
Asimismo, en una línea similar, cabe destacar un análisis reciente. Retomando la propuesta de Martuccelli en torno al examen de los soportes a la individuación, el trabajo colectivo coordinado por Di Leo y Camarotti (2013) analiza dinámicas de individuación a partir del abordaje de relatos biográficos de jóvenes pertenecientes a barrios populares. De manera complementaria a las observaciones previas, el trabajo destaca la importancia de los soportes afectivos y relacionales como recursos, en contextos en los que los soportes materiales están menos disponibles. En esta clave muestra, a la luz de los relatos, la centralidad de la propia vida personal como principal universo de comprensión en medio de una sociedad «percibida como hostil».

\section{Dispositivos de individuación: una relectura de Foucault}

Los desarrollos presentados en último lugar, orientados a visibilizar ciertas dimensiones de las tramas sociales que actúan como «soportes» para la individuación, pueden ser integrados con aquellos enfocados en los aspectos reflexivos de la subjetividad como un proceso de «interacción con el sí mismo», a partir de recursos ligados al plano de la cultura. ${ }^{7}$ La posibilidad de una convergencia entre ambas perspectivas, en todo caso, debe situarse en el marco de la revisión de las potencialidades de una noción de subjetividad que, inspirada en los desarrollos foucaultianos, es retomada de manera diferencial en cada una de estas matrices.

En este punto se trata, en suma, de potenciar un movimiento: inscribir el análisis de los procesos de individuación en el marco de dispositivos de individuación, entendidos en el sentido que Foucault (1984) reserva para la noción de dispositivo, en tanto arreglo heterogéneo de discursos, materialidades, instituciones y sujetos. Este movimiento (considerar al sujeto como un «emergente» del dispositivo y a la vez suponer la «subjetivación reflexiva») que en una lectura rápida puede suponer cierto eclecticismo conceptual, se encuentra presente en el propio mapa conceptual de Foucault. La dificultad para advertir en toda su potencia esta doble dimensión de su análisis tal vez reside en un efecto de lectura de su obra que, en clave de «los dos Foucault», ha convertido esta doble dimensión en dualismo. Desde esta visión tendríamos, por un lado, el Foucault genealógico de los «dispositivos de control» (centralmente de Vigilar y castigar (Foucault, 2004)); por otro lado, el Foucault «ético» de los «modos de subjetivación»-del segundo y tercer tomo de Historia de la sexualidad (Foucault, 2008a y 2008b)-.

De acuerdo al «primer Foucault», la individualización resultaría de una forma impuesta a los individuos mediante dispositivos de saberes/poderes: el caso, por ejemplo, de aquello que denomina «individualidad disciplinaria» en Vigilar y castigar. Mientras que el «segundo Foucault» se interesa por las «formas y las modalidades de la relación consigo mismo por las que el individuo se constituye y se reconoce como sujeto» (Foucault 2008b, 12). Este dualismo es el que se puede delinear, asimismo, entre aquellos enfoques que enfatizan en los «soportes» al individuo (en la

\footnotetext{
${ }^{7}$ En esta clave, el desafío es atender a eso que Giddens (1997) identifica como «el proyecto reflexivo del yo».
}

\section{(c) (1) $\Theta \Theta$}

Este obra está bajo una licencia de Creative Commons Reconocimiento-NoComercial-SinObraDerivada 4.0 Internacional. 
deriva «genealógica» de Castel-Martucelli), frente a los que focalizan en los procesos reflexivos de individuación (en la deriva «ética» de Goldman).

Sin embargo, retomando el trabajo de Potte-Bonneville, Corcuff propone una lectura de Foucault que plantea conexiones entre estas dos dimensiones, en lo que señala como «el cruce entre normas sociales y subjetivación». A riesgo de abusar de la glosa, expongo de manera textual su argumento, ya que atiende con condensada claridad a un punto medular:

Poniendo en relación los dos Foucault, Potte-Bonneville (2004) caracteriza la subjetividad foucaultiana como «a la vez libre y atada» de cara a las normas sociales. La subjetivación sería dependiente de las normas dominantes, a la vez que autorizaría un espacio de posible inventiva por parte del sujeto. En La inquietud de sí el propio Foucault se refiere a «una respuesta original en forma de una nueva estilística de la existencia» frente a lógicas sociales coactivas. [...]. Así podemos concebir constricciones sociales a las cuales puede «responder» un proceso de autonomización subjetiva [...]. Este surgimiento subjetivo es en sí forjado con relaciones sociales. Tendríamos una senda que se emancipa de la exclusividad del léxico de «las determinaciones sociales», sin pretensión de volver a una teoría sustancialista del «sujeto» como «esencia» postulada antes que cualquier relación sociohistórica. (Corcuff 2013, 109-110).

De modo sutil Foucault está contemplando, bajo la lógica de su noción de dispositivo -esto es, bajo el modo de una «pragmática de la multiplicidad» (un modo que no tiene que ver, como refiere Corcuff, con la «determinación» sociológica)-, la integración tanto de los procesos ligados a las constricciones «materiales», «institucionales» y/o «normativas» que disciplinanindividualizan, como aquellos otros procesos relacionados con las dimensiones «reflexivas» del yo, por los cuales las personas se «auto-subjetivizan». En esta integración, las instancias de «constricción» asumen un doble carácter (algo que la noción de «soporte» procura captar): son limitantes y a la vez habilitantes de instancias de subjetivación reflexivas específicas. A la luz de esta lectura, es posible resituar de un modo productivo los debates contrastados en torno a la individuación. Esto es: sin aplanar matices, potenciar el análisis de la articulación entre soportes sociales y procesos reflexivos, en el marco de dispositivos de individuación definidos.

\section{Conclusiones}

El debate en torno a los procesos sociales de constitución del individuo ha conducido, como puede leerse tras el caso argentino, a un creciente interés socio-antropológico por la problematización de las dinámicas de individuación emergentes en contextos periféricos. En efecto, en las perspectivas presentadas hemos identificado, en dialogo con la tradición francesa,

\section{(c) (1) $\$($}

Este obra está bajo una licencia de Creative Commons Reconocimiento-NoComercial-SinObraDerivada 4.0 Internacional. 
diferentes estrategias de relativización del agente social en tanto construcción sociocultural situada. Detengámonos aquí, a modo de cierre, en estas estrategias subyacentes.

Por un lado, uno de los caminos para captar la singularidad de los «individuos» en la región ha consistido en poner en perspectiva histórica el modelo de individuo emergente de la modernidad en los países centrales (independiente, autónomo, reflexivo, secularizado). En esta clave, se señalaron las características peculiares del proyecto modernizador en las sociedades periféricas, a la vez que se buscó destacar las distancias entre el ideal de individuo de la modernidad y los individuos «realmente existentes» en segmentos de estas sociedades. Esta apuesta, cabe observar, forma parte de un diagnóstico más amplio en torno a los alcances del proyecto modernizador en la región. En esta senda, por ejemplo, a comienzos de los años noventa García Canclini (2008) advertía que la modernización latinoamericana operó pocas veces mediante sustitución de lo tradicional, subrayando con ello el carácter heterogéneo de dicho proyecto, y señalando que el mismo debía comprenderse, en todo caso, «en interacción con las tradiciones persistentes» (2008, 320). Esta tesis de la modernidad «heterogénea» se articulaba asimismo con una noción correlativa de «individuo híbrido» ${ }^{8}:$ «somos individuos híbridos, que aprovechamos varios repertorios para enriquecernos, formarnos y participar en escenarios distintos, no siempre compatibles» (García Canclini 2005, 58). Esta mirada, en suma, tuvo eco en diversas indagaciones (Brunner, 1992; Sarlo 1994; Ortiz 1996; Martin-Barbero 2001; Semán 2006), que mostraron el carácter «heterogéneo» del proyecto modernizador, a la vez que destacaban la emergencia de estos individuos «híbridos» de mixturar tradiciones con diversos recursos reflexivos provenientes de la cultura de masas.

Por otro lado, más recientemente se ha buscado captar la especificidad de las dinámicas de individuación en la periferia, no ya situando en perspectiva histórica el modelo de individuo emergente de la modernidad, sino a través de una vía alternativa: poniendo en perspectiva analítica el proceso de individuación. Así, se trató de advertir la diversidad de factores que pueden conducir a la constitución de individuos en variados contextos sociales (factores entre los cuales los soportes otorgados por el Estado Social forman parte de un universo más amplio de posibles). En esta clave, Martuccelli (2010) ha sostenido la necesidad de disociar el estudio del individuo de la problemática de la modernidad. El autor observa que si queremos advertir en toda su densidad y especificidad sociológica las dinámicas de individuación en Latinoamérica, la hipótesis del «individuo hibrido» es insuficiente, y se debe desanclar el análisis de los perfiles de individuo de la apreciación del proyecto modernizador. ${ }^{9}$ En este sentido, no sería desde la comparación con un «modelo» (el

\footnotetext{
${ }^{8}$ En una conferencia de 1996, García Canclini refería que las «formas de estilización de lo individual [...] se hacen hoy en espacios distintos, que generan diferentes posibilidades de construir individuos» $(2005,57)$. En torno a estas dinámicas de estilización, destacaba que las mismas se llevan a cabo en un espacio multicultural y transestatal, en el cual la instancia del consumo se vuelve central para la individuación.

9 Para Martuccelli (2010), si bien trabajos como los de García Canclini o Martín-Barbero reconocen ciertas especificidades a los individuos en la región, sobre todo «en la medida en que implican que los individuos deben combinar elementos culturales heterogéneos» $(2010,85)$, sin embargo, «el aggiornamiento aparece a todas luces insuficiente para dar cuenta de las verdaderas diferencias» $(2010,85)$. Concluye que la temática de la modernidad en
} 
modelo del «individuo moderno») sino desde el análisis de un «proceso» (el proceso de individuación) como se llegaría a tal comprensión. Dichas apuestas son las que están presentes, por ejemplo, en los trabajos de Merklen considerados.

Señalado esto, se puede seguir el movimiento argumental presentado por Martucelli, buscando a la vez realizar un diálogo con las tesis del «individuo hibrido» latinoamericano. Con esa convergencia como horizonte es posible abordar el análisis de los procesos de individuación en un nivel local, poniendo de relieve las dinámicas sociales en las que el individuo se sitúa -en tanto factores específicos de individuación- sin descuidar la singularidad de los procesos reflexivos en torno a repertorios culturales emergentes -que la tesis del «individuo híbrido» viene a tematizar-. Aquí se ha propuesto esta hipótesis a la luz de un instrumento analítico -la noción de dispositivo de Foucault y el tipo de subjetividad que supone- que resulta clave para abordar de un modo integrado la interacción entre «soportes» y «reflexividades» en un nivel de análisis de las prácticas a la vez histórico y local. ${ }^{10}$

El desplazar la mirada hacia una lectura situada en el complejo juego local de soportes y reflexividades se presenta, en suma, como una apuesta a revisar el estudio de los procesos de constitución social del individuo en la región desde una agenda de investigación renovada. Y, en ese giro, arrojar algo más de luz a un mapa que, atravesado por la vieja disputa entre «cultura» y «sociedad», aún presenta claroscuros que merecen ser superados.

\section{Referencias}

Bourdieu, Pierre. 2007. El sentido práctico. Buenos Aires: Siglo XXI

Brunner, José. 1992. América Latina: Cultura y Modernidad. México: Grijalbo.

Castel, Robert. 1997. Las metamorfosis de la cuestión social. Una crónica del salariado. Buenos Aires: Paidós.

Castel, Robert y Claudine Haroche. 2003. Propiedad privada, propiedad social, propiedad de sí: Conversaciones sobre la construcción del individuo moderno. Rosario: Homo Sapiens.

Corcuff, Philippe. 2013. Las nuevas sociologías. Principales corrientes y debates. Buenos Aires: Siglo XXI.

Duarte, Luiz Fernando. 1986. Da vida nervosa das clases trabalhadoras urbanas. Rio De Janeiro: Jorge Zahar.

\footnotetext{
América Latina ha tenido dificultades para dar cuenta del proceso de individuación ocurrido en el Sur y, para lograrlo, hay que partir del reconocimiento de la existencia de «una pluralidad de vías de individuación» $(2010,91)$.

${ }^{10}$ Para una propuesta de análisis en este sentido el lector puede remitirse a Aliano (2015) Música, afición y subjetividad entre seguidores del Indio Solari. Un estudio sobre procesos de individuación en sectores populares. Tesis de doctorado en Ciencias Sociales, Universidad Nacional de La Plata. Allí se aborda un estudio de procesos de individuación popular como el emergente de prácticas reflexivas de afición musical entramadas en diversos soportes sociales relacionales.
}

\section{(c) (1) $\$(\Theta$}

Este obra está bajo una licencia de Creative Commons Reconocimiento-NoComercial-SinObraDerivada 4.0 Internacional. 
Di Leo, Pablo y Ana Camarotti (Ed.). 2013. «Quiero escribir mi historia». Vidas de jóvenes en barrios populares. Buenos Aires: Biblos.

Dumont, Louis. 1970. Hommo hierarchicus: ensayo sobre el sistema de castas. Madrid: Aguilar.

Elias, Norbert. 2009. El proceso de la civilización Investigaciones sociogenéticas y psicogenéticas. México: Fondo de Cultura Económica.

Foucault, Michel. 1984. Saber y verdad. Madrid: Ediciones de la Piqueta. 2004. Vigilar y castigar. El nacimiento de la prisión. Buenos Aires: Siglo XXI. 2008a. Historia de la sexualidad 2. El uso de los placeres. Buenos Aires: Siglo XXI. 2008b. Historia de la sexualidad 3. La inquietud de sí. Buenos Aires: Siglo XXI.

García Canclini, Néstor. 2005. Imaginarios urbanos. Buenos Aires: Eudeba. 2008. Culturas hibridas. Estrategias para entrar y salir de la modernidad. Buenos Aires: Paidós.

Goldman, Marcio. 1999. Alguma antropología. Rio de Janeiro: Relume-Dumará.

Giddens, Anthony. 1997. Modernidad e identidad del yo. El yo y la sociedad en la época contemporánea. Barcelona: Península.

Kessler, Gabriel y Denis Merklen. 2013. «Una introducción cruzando el Atlántico». En Individuación, precariedad, inseguridad ¿Desinstitucionalización del presente?, editado por Robert Castel, et. al. Buenos Aires: 4-20. Paidós.

Lahire, Bernard. 2005. «De la teoría del habitus a una sociología psicológica». En El trabajo sociológico de Pierre Bourdieu. Deudas y críticas, dirigido por Bernard Lahire: 143-179. Buenos Aires: Siglo XXI.

Martín, Eloísa. 2007. «Aportes al concepto de 'religiosidad popular': una revisión de la bibliografía argentina». En Ciencias sociales y religión en América Latina. Perspectivas en debate, coordinado por Carozzi, María y Cesar Ceriani Cernadas: 20-34. Buenos Aires: Biblos.

Martín-Barbero, Jesús. 2001. Al sur de la modernidad. Comunicación, globalización y multiculturalidad. Instituto Internacional de Literatura Iberoamericana: Universidad de Pittsburg.

Martuccelli, Danilo. 2007. Gramáticas del individuo. Buenos Aires: Losada. 2010. ¿Existen individuos en el sur? Santiago de Chile: LOM.

Merklen, Denis. 2005. Pobres ciudadanos. Las clases populares en la era democrática (Argentina, 1983- 2003). Buenos Aires: Gorla.

2013. «Las dinámicas contemporáneas de la individuación» En Individuación, precariedad, inseguridad ¿Desinstitucionalización del presente? Editado por Robert Castel, et. al. Buenos Aires: 45-86. Paidós.

Míguez, Daniel y Semán, Pablo. 2006. «Diversidad y recurrencia en las culturas populares actuales». En Entre santos, cumbias y piquetes. Las culturas populares en la Argentina reciente, editado por Míguez, Daniel y Pablo Semán: 11-32. Buenos Aires: Biblos.

\section{(c) (1) $\$(\Theta$}

Este obra está bajo una licencia de Creative Commons Reconocimiento-NoComercial-SinObraDerivada 4.0 Internacional. 
Ortiz, Renato. 1996. Otro territorio. Ensayos sobre el mundo contemporáneo. Quilmes: Universidad Nacional de Quilmes.

Rosanvallon, Pierre. 1997. La nueva cuestión social. Buenos Aires: Manantial.

Sarlo, Beatriz. 1994. Escenas de la vida posmoderna. Buenos Aires: Ariel.

Semán, Pablo. 2006. Bajo continuo. Exploraciones descentradas sobre cultura popular y masiva. Buenos Aires: Gorla.

2007. «Psicologización y religión en un barrio del Gran Buenos Aires». Debates do NER, 12: 9-44.

Semán, Pablo y Guadalupe Gallo. 2008. «Rescate y sus consecuencias. Cultura y religión: sólo en singular». Ciencias Sociales y Religión, 10: 73-94.

Svampa, Maristella. 2009. «Identidades astilladas. De la patria metalúrgica al heavy metal», en: Desde abajo. La transformación de las identidades sociales, editado por Maristella Svampa, 121-154. Buenos Aires: Biblos.

Velho, Gilberto. 1997. Individualismo e cultura. Notas para uma Antropología da Sociedade Contemporânea. Rio de Janeiro: Zahar. 